J Am Acad Dermatol. 2018 November ; 79(5): 904-912.e1. doi:10.1016/j.jaad.2018.05.1257.

\title{
Fibroproliferative genes are preferentially expressed in central centrifugal cicatricial alopecia
}

\author{
Crystal Aguh, MD ${ }^{\mathrm{a}}$, Yemisi Dina, BS ${ }^{\mathrm{b}}$, C. Conover Talbot Jr, BS ${ }^{\mathrm{c}}$, and Luis Garza, MD, PhD \\ aDepartment of Dermatology, Johns Hopkins School of Medicine, Baltimore \\ bMeharry Medical College, Nashville \\ cJohns Hopkins Medical Institute Deep Sequencing and Microarray Core, Baltimore.
}

\begin{abstract}
Background: Central centrifugal cicatricial alopecia (CCCA) is a primary cicatricial alopecia that most commonly affects women of African descent. Like CCCA, fibroproliferative disorders (FPDs) such as keloids, atherosclerosis, and fibroids are characterized by low-grade inflammation and irritation, resulting in end-stage fibrosis.
\end{abstract}

Objective: We sought to determine whether fibroproliferative genes were up-regulated in patients with CCCA.

Methods: A total of 5 patients with biopsy-proven CCCA were recruited for this study. Two scalp biopsy specimens were obtained from each patient; 1 from CCCA-affected vertex scalp and 1 from the unaffected occipital scalp. Microarray analysis was performed to determine the differential gene expression patterns.

Results: There was an upregulation of genes implicated in FPDs in patients with CCCA. Specifically, we noted increased expression of platelet derived growth factor gene ( $P D G F)$, collagen I gene (COL I), collagen III gene (COL III), matrix metallopeptidase 1 gene (MMPI), matrix metallopeptidase 2 gene (MMP2), matrix metallopeptidase 7 gene (MMP7), and matrix metallopeptidase 9 gene (MMP9) in affected scalp compared with in unaffected scalp. Significant overlap in the canonic pathways was noted between patients with CCCA and patients with both atherosclerosis and hepatic fibrosis $(P<.001)$.

Limitations: Small sample size and the use of whole skin tissue for analysis.

Conclusion: We have identified the upregulation of critical genes implicated in FPDs in the gene expression profile of patients with CCCA. These findings may help identify future therapeutic targets for this otherwise difficult-to-treat condition. ( J Am Acad Dermatol 2018;79:904-12.)

\section{Keywords}

alopecia; central centrifugal cicatricial alopecia; cicatricial alopecia; fibroproliferative disorders; fibrosis; therapy

Reprint requests: Crystal Aguh, MD, MFL Center Tower, Suite 2500, 5200 Eastern Ave, Baltimore, MD 21224. cagi1 @jhmi.edu. Conflicts of interest: None disclosed. 


\section{INTRODUCTION}

Central centrifugal cicatricial alopecia (CCCA) is a lymphocytic primary cicatricial alopecia that most commonly affects women of African descent, and the pathophysiology of this disease remains a mystery. ${ }^{1,2}$ Although a true prevalence rate has yet to be established, some studies estimate that 1 in 15 black women older than 50 years suffer from this condition. ${ }^{3}$ Hair loss typically begins on the vertex of the scalp and gradually progresses outward centrifugally. 1,2,4 Although CCCA can display histologic features that overlap with those of other forms of hair loss, unlike patients with primary cicatricial alopecias, in whom appreciable inflammation is the norm, patients with CCCA can often present with minimal to seemingly absent clinical signs of inflammation on examination. ${ }^{1,5,6}$ Eventually, patients develop diffuse fibrosis, which often occurs out of proportion to the clinical and histologic signs of inflammation. ${ }^{1,5}$

\section{Pathophysiology of FPDs}

Fibroproliferative disorders (FPDs) is an umbrella term that encapsulates a variety of conditions characterized by aberrant wound healing and excessive fibrosis. Like CCCA, FPDs such as systemic sclerosis, keloids, atherosclerosis, and uterine fibroids (UFs) are all characterized by persistent low-grade inflammation and irritation that results in end-stage fibrosis. ${ }^{7,8}$ The risk of certain FPDs is increased in people of African descent, and this increased risk is thought to be secondary to the protective effect that profibrotic alleles offer against helminths found in Sub-Saharan Africa. 8,9

In normal wound healing, injury to the skin induces a cascade of events that begins with clot formation and hemostasis. ${ }^{10}$ The amount of collagen deposited in wounds is controlled by a delicate balance of extracellular matrix (ECM) deposition and degradation. However, in FPDs this equilibrium is disturbed, leading to excess ECM deposition and persistent fibrogenesis that occurs independently of sustained inflammation. Although there is heterogeneity of up-regulated markers between FPDs, a number of genes have been consistently implicated in the pathogenesis of FPDs. These include transforming growth factor beta gene $(T G F B)$, platelet derived growth factor gene $(P D G F)$, vascular endothelial growth factor gene $(V E G F)$, matrix metalloproteinase matrix metalloproteinase gene 1 (MMP1), matrix metalloproteinase matrix metalloproteinase gene 2 (MMP2), matrix metalloproteinase matrix metalloproteinase gene 7 (MMP7), and matrix metalloproteinase matrix metalloproteinase gene 9 (MMP9) among others. ${ }^{10-14}$

\section{Overlap between FPDs and CCCA}

This process of excess fibrosis leading to permanent scar tissue formation in FPDs is similar to the process seen in CCCA, in which thick fibrous tracts replace hair follicles. ${ }^{1}$ A recent study has shown that UFs are nearly 5 times more common in women with CCCA than in race-and sex-matched controls. ${ }^{9}$ Given that CCCA and FPDs most commonly affect patients of African descent, coupled with the association between CCCA and a common FPD, we sought to determine the overlap in gene expression between CCCA and other FPDs. 


\section{METHODS}

This study was approved by the Johns Hopkins Hospital institutional review board. Informed consent was obtained from all patients with approval from the Johns Hopkins ethics board. A total of 5 patients with biopsy-proven CCCA were recruited for this study. Two scalp biopsy specimens were obtained from each patient; 1 from CCCA-affected vertex scalp and 1 from the unaffected occipital scalp, which served as an intrascalp control. No patients had received treatment for CCCA before the skin sampling.

\section{RNA isolation and microarray analysis}

Once obtained, fresh tissue samples were immediately submerged in a 2-mL tube containing RNAlater (Qiagen, Valencia, CA) stabilization reagent. Tissue was stored at $4^{\circ} \mathrm{C}$ for 24 hours and then transferred to a freezer for long-term storage at e $80^{\circ} \mathrm{C}$. Total RNA was extracted by using a Qiagen RNeasy fibrous tissue kit (Qiagen, Valencia, CA). Tissue homogenization and total RNA extraction were performed according to the standard protocols. Bioanalyzer measurements of RNA quality and concentration measurements were performed before microarray analysis.

Samples were analyzed by using the Affymetrix Clariom S microarray (Affymetrix, Santa Clara, CA), which provides transcriptome-wide analysis of more than 20,000 well-annotated human genes, interrogating all known exons. The array data were imported and normalized by using the Robust Multi-Array Averaging protocol with the Partek Genomics Suite analytic platform (version 6.6, Partek, Inc., Chesterfield, MO).

Functional annotation was conducted via gene ontology, which allowed for identification of over-represented gene function categories among up-regulated or down-regulated genes to better understand the gene profile results. Special attention was paid to gene products that have been implicated in FPDs and other cicatricial alopecias.

Differential gene expression between the experimental classes was evaluated with the paired-sample 2-tailed $t$ test algorithm to determine the transcripts' fold changes and their statistical significance, as measured by the standard deviation (SD) (from unchanged) and $P$ values.

\section{RESULTS}

Gene expression patterns between affected scalp and intrascalp paired healthy controls were directly compared with each other. More than 21,000 genes were identified and arranged by fold change. A total of 858 genes were noted to have a fold change of more than 2 SDs. Of those, 413 were up-regulated and 445 were down-regulated in affected scalp.

\section{Increased expression of genes that regulate fibrosis and are implicated in FPDs}

The genes that were noted to be up-regulated in CCCA-affected scalp tissue include several implicated in FPDs and the regulation of fibroblast proliferation (Fig 1). The largest group of up-regulated genes consisted of those involved in ECM organization. A total of 30 of 188 genes regulating ECM organization were noted to be up-regulated $(P<.001$ [Table I]). These 
included fibroblast activation protein alpha gene (FAP); collagen I gene (COLI), collagen III gene (COLIII), collagen V gene (COLV), collagen XI gene (COLXI), and fibrillin 1 gene $(F B N 1)$, as well as genes involved in cell adhesion, such as integrin and laminin subunits. In addition, $M M P 1, M M P 2, M M P 7, M M P 9$, matrix metalloproteinase gene 13 (MMP13), and matrix metalloproteinase gene 15 (MMP15) were all up-regulated more than 2 SDs above the mean based on fold change.

The role of MMPs in FPDs has been studied extensively. ${ }^{11,12}$ Although the role of MMPs is to break down ECM, certain MMPs have been implicated in FPDs such as idiopathic pulmonary fibrosis (IPF) and hepatic fibrosis. ${ }^{11}$ In particular, $M M P 1, M M P 2, M M P 7$, matrix metalloproteinase gene $8(M M P 8)$, and $M M P 9$ have all been associated with increased fibrosis and are up-regulated in certain FPDs. ${ }^{11,13}$ Both $M M P 2$ and $M M P 9$ have been associated with fibrocyte migration to healing tissue, which is the source of myofibroblasts implicated in fibrosis. ${ }^{11} M M P 1$ and $M M P 7$ are also consistently upregulated in IPF and have been suggested as possible biomarkers of disease. ${ }^{11}$

Of note, 6 of the 50 genes known to regulate fibroblast proliferation showed increased expression in CCCA tissue, including fibronectin 1 ( $F N 1)$, platelet derived growth factor receptor alpha gene (PDGFRA), and platelet derived growth factor receptor beta gene $(P D G F R B)(P=.024) . F N 1$ and $P D G F$ have both been implicated in the pathogenesis of FPDs. ${ }^{10} P D G F$ plays a key role in the migration and proliferation of fibroblasts and also stimulates the recruitment of myofibroblasts, which are a key cell regulator of fibroproliferation. ${ }^{11,12}$ In turn, these myofibroblasts secrete fibronectin, which further encourages excess ECM deposition.

Additionally, 13 of 45 genes noted to regulate endodermal cell differentiation were upregulated in affected tissue (including several collagens, cell adhesion molecules such as integrin and laminin subunits, and MMPs $)(P<.001)$ Together, these genes reflect the increased collagen turnover and ECM remodeling that form a key component of sustained fibrosis seen in patients with FPDs. ${ }^{10,12,14}$

Finally, 12 of 39 genes associated with organization of collagen fibril were preferentially expressed in diseased tissue $(P<.001)$.

\section{Decreased expression of genes regulating lipid metabolism and biosynthesis of fatty acids}

The genes that were down-regulated in CCCA-affected tissue include those with roles in lipid metabolism, the hair cycle, and fatty acid biosynthesis (Table II). In CCCA-affected scalp, 66 of 836 genes that regulate the lipid metabolic process were down-regulated $(P<$. 001). ${ }^{15-17}$ This includes genes such as apolipoprotein $\mathrm{C} 1$ gene (APOCI), apolipoprotein $\mathrm{E}$ gene $(A P O E)$, ELOVL fatty acid elongase 3 gene (ELOVL3), ELOVL fatty acid elongase 3 gene ( $E L O V L 5)$, fatty acid 2-hydroxylase gene $(F A 2 H)$, and stearoyl-CoA desaturase 5 gene (SCD5). Lipids play an important role in hair follicle homeostasis, and members of the SCD family have been found to play a role in maintaining sebaceous glands. ${ }^{18}$ Transgenic mice lacking stearoyl-CoA desaturase 1 gene $(S C D 1)$ display a depletion of sebaceous lipids and alopecia and are proposed to be a model for scarring alopecia. ${ }^{18}$ Similarly, the loss of 
FA2H has been linked to altered sebum composition and cyclic alopecia in the mouse model. 19

Of 34 genes that are related to the biosynthesis of unsaturated fatty acids, 7 were downregulated in scalp tissue affected by CCCA $(P<.001)$. ELOVL 3 was notable among these 7 genes, as $E L O V L 3$-deficient mice have been found to exhibit a hyper-plastic pilosebaceous system and a sparse hair coat. ${ }^{20}$ Lastly, 13 of 89 genes associated with the hair cycle process, including leucine-rich repeat-containing $\mathrm{G}$ protein coupled receptor 5 gene (LGR5), were down-regulated in diseased tissue. LGR5-positive cells belong to a stem cell population that is able to generate new hair follicles and maintain hair follicle cell lineages over a long period of time..$^{21,22}$ Additionally, loss of $L G R 5$ has been found in the affected scalp of men with androgenetic alopecia. ${ }^{22}$

\section{Ingenuity pathway analysis}

We analyzed our microarray data by using Qiagen's Ingenuity Pathway Analysis (IPA) software. IPA is a robust bioinformatics search tool that utilizes the Ingenuity Knowledge Base to identify the most significant pathways within a data set. Our data showed that of all the canonic pathways analyzed with Qiagen IPA software, the greatest overlap was displayed by the hepatic fibrosis (16.5\% overlap) and atherosclerosis signaling (18\% overlap) pathways, both of which are PFDs (Table III).

\section{DISCUSSION}

To our knowledge, this is the first published study of gene expression patterns in patients with CCCA. In this study, we used DNA microarrays to determine whether there is increased expression of fibroproliferative genes in patients with CCCA by comparing the expression profile of CCCA with that of other known FPDs. Through the use of IPA software, we found that our CCCA microarrays displayed the greatest overlap with hepatic fibrosis and atherosclerosis, which are 2 well-known FPDs. This discovery correlated with our findings revealing that several genes responsible for fibroblast activation, excess collagen deposition, and aberrant wound healing were up-regulated in CCCA-affected scalp compared with in unaffected scalp. A thorough review of the current literature showed a substantial overlap between the expression pattern of fibroproliferative genes in patients with CCCA and that in patients with other known FPDs (Table IV, ${ }^{14,23-63}$ ). Of note, CCCA displayed the greatest overlap with IPF and UFs. This finding is supported by a prior study by our group in which we found that patients with CCCA are more likely to develop fibroids than their counterparts are. ${ }^{9}$ Additionally, we noted increased expression of PDGF, COLI, COLII, COLIII, MMP1, MMP2, MMP7, and MMP9, all of which have been implicated in other FPDs. ${ }^{13,14,23}$ The increased expression of these select MMPs is particularly notable. Though MMPs are typically responsible for collagen catabolism, certain MMPs are thought to induce fibrocyte migration, eventually giving rise to myofibroblasts, which are the key cell type responsible for the excess fibrosis seen in FPDs. ${ }^{13}$

We also noted a decrease in genes that regulate lipid metabolism. Aberrant lipid metabolism has been implicated in other forms of alopecia, namely, lichen planopilaris. ${ }^{64,65}$ Specifically, the decreased expression of peroxisome proliferator associated receptor gamma (PPARG) is 
thought to incite an inflammatory response that leads to destruction of the pilosebaceous unit in primary scarring alopecias. ${ }^{64,65}$ Interestingly, no difference was noted in PPARG expression when CCCA-affected scalp was compared with unaffected scalp; instead, there might be adjustments of protein abundance or modification that were not tested here. This may suggest that the PPARG transcriptional changes are not a primary mediator of this phenotype of cicatricial alopecia seen in patients with CCCA.

Although there are no consensus treatments for CCCA, the mainstay of therapy remains anti-inflammatory medications such as topical and intralesional steroids, and the response is often disappointing. ${ }^{1,4}$ However, unlike in patients with other primary cicatricial alopecias, it is not unusual for patients with CCCA to present without appreciable inflammation on the scalp, even as the disease is progressing. ${ }^{1,5,6}$ Patients with early-stage CCCA, however, may exhibit a lymphocytic infiltrate on histology. 1,4

In FPDs, though inflammation is often the inciting event that leads to fibrosis, persistent fibrogenesis occurs independent of sustained inflammation. ${ }^{10,66}$ This may partially explain the limited efficacy of anti-inflammatory medications in FPDs. ${ }^{10}$ We propose that a similar consideration be made in patients with CCCA. Though the cause of initial irritation to the scalp remains unclear, it may be attributed to 1 of many factors, including hair styling practices, seborrheic dermatitis, and subclinical inflammation due to androgenetic alopecia. Any one of these factors may spur long-term persistent fibrogenesis, even in the absence of continued inflammation. Although anti-inflammatory therapies are helpful to some patients, they may not be sufficient to halt disease progression in all patients, as has been the experience of 2 of our authors (C.A. and L.G.). Investigation of the use of therapies targeting fibrosis in the treatment of CCCA may be warranted, as such therapies have shown some promise in other FPDs. ${ }^{67-69}$ Our data suggest that losartan, atorvastatin, and lovastatin may be reasonable therapeutic targets that are worthy of further investigation in CCCA (Supplemental Fig 1, A-C; available at http://www.jaad.org). However, FPDs are notoriously difficult to treat, and further research is required to identify targeted therapies for fibrosis.

This study is limited by the use of a small sample of patients and the use of whole skin tissue for analysis. Future studies may glean more information about the fibroproliferative properties of CCCA by isolating the gene expression patterns of fibroblasts in diseased scalp. Further studies are needed to establish a mechanistic pathway for the development of CCCA. Here, we have identified the upregulation of critical genes implicated in FPDs in the gene expression profile of patients with CCCA. These findings may help identify future therapeutic targets for this otherwise difficult-to-treat condition.

\section{Supplementary Material}

Refer to Web version on PubMed Central for supplementary material.

\section{Acknowledgments}

Funding sources: Supported by the Dr Stanford Lamberg Research Award. Ms Dina is a participant of the Vanderbilt Medical Scholars Program and is partially funded by a National Institutes of Health Clinical and 
Translational Science Awards grant (UL1 RR 024975). Dr Garza was supported by grants R01AR064297 and AR068280 from the National Institute of Arthritis and Musculoskeletal and Skin Diseases, which is part of the National Institutes of Health.

\section{Abbreviations used:}

$\begin{array}{ll}\text { CCCA } & \text { central centrifugal cicatricial alopecia } \\ \text { ECM } & \text { extracellular matrix } \\ \text { FPD } & \text { fibroproliferative disorder } \\ \text { IPA } & \text { Ingenuity Pathway Analysis } \\ \text { IPF } & \text { idiopathic pulmonary fibrosis } \\ \text { SD } & \text { standard deviation } \\ \text { UF } & \text { uterine fibroid }\end{array}$

\section{REFERENCES}

1. Ogunleye TA, McMichael A, Olsen EA. Central centrifugal cicatricial alopecia. Dermatol Clin 2014;32(2):173-181. [PubMed: 24680004]

2. Bolduc C, Sperling LC, Shapiro J. Primary cicatricial alopecia. J Am Acad Dermatol 2016;75(6): 1101-1117. [PubMed: 27846945]

3. Khumalo NP, Jessop S, Gumedze F, Ehrlich R. Hairdressing and the prevalence of scalp disease in African adults. Br J Dermatol 2007;157(5):981-988. [PubMed: 17725667]

4. Gathers RC, Lim HW. Central centrifugal cicatricial alopecia: past, present, and future. J Am Acad Dermatol 2009;60(4): 660-668. [PubMed: 19293013]

5. Gathers RC, Jankowski M, Eide M, Lim HW. Hair grooming practices and central centrifugal cicatricial alopecia. J Am Acad Dermatol 2009;60(4):574-578. [PubMed: 19293007]

6. Ross EK, Tan E, Shapiro J. Update on primary cicatricial alopecias. J Am Acad Dermatol 2005;53(1):1-37. [PubMed: 15965418]

7. Huang C, Ogawa R. Fibroproliferative disorders and their mechanobiology. Connect Tissue Res 2012;53(3):187-196. [PubMed: 22329637]

8. Hellwege JN, Torstenson ES, Russell SB, Edwards TL, Edwards DRV. Evidence of selection as a cause for racial disparities in fibroproliferative disease. PLoS OneE 2017;12(8): e0182791.

9. Dina Y, Okoye GA, Aguh C. Association of uterine leiomyomas with central centrifugal cicatricial alopecia. JAMA Dermatol 2018;154(2):213-214. [PubMed: 29282458]

10. Wynn TA. Common and unique mechanisms regulate fibrosis in various fibroproliferative diseases. J Clin Invest 2007; 117(3):524-529. [PubMed: 17332879]

11. Pardo A, Selman M. Role of matrix metaloproteases in idiopathic pulmonary fibrosis. Fibrogenesis Tissue Repair 2012;5(Suppl 1):S9. [PubMed: 23259796]

12. Wynn T. Cellular and molecular mechanisms of fibrosis. J Pathol 2008;214(2):199-210. [PubMed: 18161745]

13. Pardo A, Cabrera S, Maldonado M, Selman M. Role of matrix metalloproteinases in the pathogenesis of idiopathic pulmonary fibrosis. Respir Res 2016;17 10.1186/s12931-016-0343-6.

14. Tredget EE. Pathophysiology and treatment of fibroproliferative disorders following thermal injury. Ann N Y Acad Sci 1999;888(1):165-182. [PubMed: 10842632]

15. Colombe L, Vindrios A, Michelet J-F, Bernard BA. Prostaglandin metabolism in human hair follicle. Exp Dermatol 2007;16(9):762-769. [PubMed: 17697149]

16. Yanagida K, Ishii S. Non-Edg family LPA receptors: the cutting edge of LPA research. J Biochem 2011;150(3):223-232. [PubMed: 21746769] 
17. Yamamoto K, Taketomi Y, Isogai Y, et al. Hair follicular expression and function of group X secreted phospholipase A2 in mouse skin. J Biol Chem 2011;286(13):11616-11631. [PubMed: 21266583]

18. Guillou H, Zadravec D, Martin PGP, Jacobsson A. The key roles of elongases and desaturases in mammalian fatty acid metabolism: insights from transgenic mice. Prog Lipid Res 2010;49(2):186199. [PubMed: 20018209]

19. Maier H, Meixner M, Hartmann D, et al. Normal fur development and sebum production depends on fatty acid 2-hydroxylase expression in sebaceous glands. J Biol Chem 2011;286(29):2592225934. [PubMed: 21628453]

20. Westerberg R, Tvrdik P, Und'en A-B, et al. Role for ELOVL3 and fatty acid chain length in development of hair and skin function. J Biol Chem 2004;279(7):5621-5629. [PubMed: 14581464]

21. Jaks V, Barker N, Kasper M, et al. Lgr5 marks cycling, yet long-lived, hair follicle stem cells. Nat Genet 2008;40(11): 1291-1299. [PubMed: 18849992]

22. Garza LA, Yang C-C, Zhao T, et al. Bald scalp in men with androgenetic alopecia retains hair follicle stem cells but lacks CD200-rich and CD34-positive hair follicle progenitor cells. J Clin Invest 2011;121(2):613-622. [PubMed: 21206086]

23. Chin GS, Liu W, Peled Z, et al. Differential expression of transforming growth factor- $\beta$ receptors I and II and activation of Smad 3 in keloid fibroblasts. Plast Reconstr Surg 2001; 108(2):423-429. [PubMed: 11496185]

24. Lafyatis R Transforming growth factor bdat the centre of systemic sclerosis. Nat Rev Rheumatol 2014;10:706. [PubMed: 25136781]

25. Fernandez I, Eickelberg O. The impact of TGF- $\beta$ on lung fibrosis: from targeting to biomarkers. Proc Am Thorac Soc 2012;9:111-116. [PubMed: 22802283]

26. Shen T, Shi H, Xu Q, Song Q, Xu Y, Huang Y. Effects of TGF- $\beta$ on uterine fibroids of women of childbearing age and uterine artery embolization. Minim Invasive Ther Allied Technol 2017; 26(5):292-299. [PubMed: 28318365]

27. Klareskog L, Gustafsson R, Scheynius A, H€allgren R. Increased expression of platelet-derived growth factor type $\mathrm{B}$ receptors in the skin of patients with systemic sclerosis. Arthritis Rheum 2005;33(10):1534-1541.

28. Antoniades HN, Bravo MA, Avila RE, et al. Platelet-derived growth factor in idiopathic pulmonary fibrosis. J Clin Invest 1990;86(4):1055-1064. [PubMed: 2170444]

29. Suo G, Jiang Y, Cowan B, Wang JYJ. Platelet-derived growth factor C is upregulated in human uterine fibroids and regulates uterine smooth muscle cell growth. Biol Reprod 2009;81(4):749758. [PubMed: 19553600]

30. Hamaguchi Y, Fujimoto M, Matsushita T, Hasegawa M, Takehara K, Sato S. Elevated serum insulin-like growth factor (IGF-1) and IGF binding protein-3 levels in patients with systemic sclerosis: possible role in development of fibrosis. J Rheumatol 2008;35(12):2363-2371. [PubMed: 19004037]

31. Cao B, Guo Z, Zhu Y, Xu W. The potential role of PDGF, IGF-1, TGF-beta expression in idiopathic pulmonary fibrosis. Chin Med J 2000;113(9):776-782. [PubMed: 11776068]

32. Mu Y, He J, Yan R, Hu X, Liu H, Hao Z. IGF-1 and VEGF can be used as prognostic indicators for patients with uterine fibroids treated with uterine artery embolization. Exp Ther Med 2016;11(2): 645-649. [PubMed: 26893660]

33. Smith JC, Boone BE, Opalenik SR, Williams SM, Russell SB. Gene profiling of keloid fibroblasts shows altered expression in multiple fibrosis-associated pathways. J Invest Dermatol 2008;128(5): 1298-1310. [PubMed: 17989729]

34. Bi S, Chai L, Yuan X, Cao C, Li S. MicroRNA-98 inhibits the cell proliferation of human hypertrophic scar fibroblasts via targeting Col1A1. Biol Res 2017;50:22. [PubMed: 28629444]

35. Louneva N, Saitta B, Herrick DJ, Jimenez SA. Transcriptional inhibition of type I collagen gene expression in scleroderma fibroblasts by the antineoplastic drug ecteinascidin 743 . J Biol Chem 2003;278(41):40400-40407. [PubMed: 12881530] 
36. Emblom-Callahan MC, Chhina MK, Shlobin OA, et al. Genomic phenotype of non-cultured pulmonary fibroblasts in idio-pathic pulmonary fibrosis. Genomics 2010;96(3):134-145. [PubMed: 20451601]

37. Ciavattini A, Di Giuseppe J, Stortoni P, et al. Uterine fibroids: pathogenesis and interactions with endometrium and endo-myometrial junction. Obstet Gynecol Int 2013;2013:173184. [PubMed: 24163697]

38. Gauglitz GG, Bureik D, Dombrowski Y, Pavicic T, Ruzicka T, Schauber J. Botulinum toxin A for the treatment of keloids. Skin Pharmacol Physiol 2012;25(6):313-318. [PubMed: 22948093]

39. Kikuchi K, Hartl CW, Smith EA, LeRoy EC, Trojanowska M. Direct demonstration of transcriptional activation of collagen gene expression in systemic sclerosis fibroblasts: insensitivity to TGF $\beta 1$ stimulation. Biochem Biophys Res Comm 1992; 187(1):45-50. [PubMed: 1520334]

40. Konishi K, Gibson KF, Lindell KO, et al. Gene expression profiles of acute exacerbations of idiopathic pulmonary fibrosis. Am J Respir Crit Care Med 2009;180(2):167-175. [PubMed: 19363140]

41. Zaitseva M, Vollenhoven BJ, Rogers PAW. In vitro culture significantly alters gene expression profiles and reduces differences between myometrial and fibroid smooth muscle cells. Mol Hum Reprod 2006;12(3):187-207. [PubMed: 16524927]

42. Zhang G-Y, Wu L-C, Liao T, et al. A novel regulatory function for miR-29a in keloid fibrogenesis. Clin Exp Dermatol 2015; 41(4):341-345. [PubMed: 26566758]

43. Yang Y, Wei P, Guo XJ, et al. Impact of age and autoantibody status on the gene expression of scleroderma fibroblasts in response to silica stimulation. Eur J Inflamm 2013;11(3):631. [PubMed: 25435887]

44. Zhang X, Liu H, Hock T, Thannickal VJ, Sanders YY. Histone deacetylase inhibition downregulates collagen 3A1 in fibrotic lung fibroblasts. Int J Mol Sci 2013;14(10):19605-19617. [PubMed: 24084714]

45. Kischer CW, Hendrix MJC. Fibronectin (FN) in hypertrophic scars and keloids. Cell Tissue Res 1983;231(1):29-37. [PubMed: 6342808]

46. Cooper SM, Keyser AJ, Beaulieu AD, Ruoslahti E, Nimni ME, Quismorio FP. Increase in fibronectin in the deep dermis of involved skin in progressive systemic sclerosis. Arthritis Rheum 1979;22(9):983-987. [PubMed: 383087]

47. Lehtonen ST, Veijola A, Karvonen H, et al. Pirfenidone and nintedanib modulate properties of fibroblasts and myofibro-blasts in idiopathic pulmonary fibrosis. Respir Res 2016;17 10.1186/ s12931-016-0328-5.

48. Halder SK, Osteen KG, Al-Hendy A. 1,25-Dihydroxyvitamin D3 reduces extracellular matrixassociated protein expression in human uterine fibroid cells. Biol Reprod 2013;89(6):150. [PubMed: 24174578]

49. Salem A, Assaf M, Helmy A, et al. Role of vascular endothelial growth factor in keloids: a clinicopathologic study. Int J Dermatol 2009;48(10):1071-1077. [PubMed: 19775400]

50. Zhang Y, Li H, Wang X, et al. Morphology of hypertrophic scar tissues and expressions of vascular endothelial growth factor and transforming growth factor beta activated kinase 1 in these tissues. Zhongguo Yi Xue Ke Xue Yuan Xue Bao 2015; 37(4):446-450. [PubMed: 26564463]

51. Davies CA, Jeziorska M, Freemont AJ, Herrick AL. The differential expression of VEGF, VEGFR-2, and GLUT-1 proteins in disease subtypes of systemic sclerosis. Hum Pathol 2006; 37(2):190-197. [PubMed: 16426919]

52. Murray LA, Habiel DM, Hohmann M, et al. Antifibrotic role of vascular endothelial growth factor in pulmonary fibrosis. JCI Insight 2017;2(16):92192. [PubMed: 28814671]

53. Sang PF, Wang H, Wang M, et al. NEDD4-1 and PTEN expression in keloid scarring. Genet Mol Res 2015;14(4): 13467-13475. [PubMed: 26535660]

54. Guo L, Chen L, Bi S, et al. PTEN inhibits proliferation and functions of hypertrophic scar fibroblasts. Mol Cell Biochem 2012;361(1-2):161-168. [PubMed: 21989717]

55. Parapuram SK, Shi-wen X, Elliott C, et al. Loss of PTEN expression by dermal fibroblasts causes skin fibrosis. J Invest Dermatol 2011;131(10):1996-2003. [PubMed: 21654839] 
56. Xia H, Khalil W, Kahm J, Jessurun J, Kleidon J, Henke CA. Pathologic caveolin-1 regulation of PTEN in idiopathic pulmonary fibrosis. Am J Pathol 2010;176(6):2626-2637. [PubMed: 20395445]

57. Makker A, Goel MM, Mahdi AA, et al. PI3K/Akt/mTOR signaling \& its regulator tumour suppressor genes PTEN\& LKB1 in human uterine leiomyomas. Indian J Med Res 2016; 143(Supplement):S112-S119. [PubMed: 27748285]

58. Lee DE, Trowbridge RM, Ayoub NT, Agrawal DK. High--mobility group box protein-1, matrix metalloproteinases, and vitamin D in keloids and hypertrophic scars. Plast Reconstr Surg Glob Open 2015;3(6). 10.1097/GOX.0000000000000391.

59. Craig VJ, Zhang L, Hagood JS, Owen CA. Matrix metalloproteinases as therapeutic targets for idiopathic pulmonary fibrosis. Am J Respir Cell Mol Biol 2015;53(5):585-600. [PubMed: 26121236]

60. Kuroda K, Shinkai H. Gene expression of types I and III collagen, decorin, matrix metalloproteinases and tissue inhibitors of metalloproteinases in skin fibroblasts from pa-tients with systemic sclerosis. Arch Dermatol Res 1997; 289(10):567-572. [PubMed: 9373715]

61. Travis TE, Ghassemi P, Prindeze NJ, et al. Matrix metalloproteinases are differentially regulated and responsive to compression therapy in a red Duroc model of hypertrophic scar. Eplasty 2018;18:e1. [PubMed: 29375731]

62. Moinzadeh P, Krieg T, Hellmich M, et al. Elevated MMP-7 levels in patients with systemic sclerosis: correlation with pulmonary involvement. Exp Dermatol 2011;20(9):770-773. [PubMed: 21707759]

63. Kim W-U, Min S-Y, Cho M-L, et al. Elevated matrix metalloproteinase-9 in patients with systemic sclerosis. Arthritis Res Ther 2005;7(1):R71-R79. [PubMed: 15642145]

64. Karnik P, Tekeste Z, Mccormick TS, et al. Hair follicle stem cell-specific PPARg deletion causes scarring alopecia. J Investig Dermatol Lond 2009;129(5):1243-1257.

65. Mirmirani P, Karnik P. Lichen planopilaris treated with a peroxisome proliferator-activated receptor $g$ agonist. Arch Dermatol 2009;145(12):1363-1366. [PubMed: 20026843]

66. Bitterman PB, Henke CA. Fibroproliferative disorders. Chest 1991;99(3):81S-84S. [PubMed: 1997286]

67. Chiaramonte MG, Donaldson DD, Cheever AW, Wynn TA. An IL-13 inhibitor blocks the development of hepatic fibrosis during a T-helper type 2-dominated inflammatory response. J Clin Invest 1999;104(6):777-785. [PubMed: 10491413]

68. Chiaramonte MG, Mentink-Kane M, Jacobson BA, et al. Regulation and function of the interleukin 13 receptor $a 2$ during a T helper cell type 2-dominant immune response. J Exp Med 2003;197(6): 687-701. [PubMed: 12642601]

69. Bhattacharyya S, Wei J, Tourtellotte WG, Hinchcliff M, Gottardi CG, Varga J. Fibrosis in systemic sclerosis: common and unique pathobiology. Fibrogenesis Tissue Repair 2012; 5(1):S18.

[PubMed: 23259815] 


\section{CAPSULE SUMMARY}

- Both central centrifugal cicatricial alopecia (CCCA) and fibroproliferative disorders commonly affect patients of African descent.

- Critical genes implicated in fibroproliferative disorders are up-regulated in CCCA-affected scalp tissue.

- $\quad$ Antifibrotic therapies may play a role in the treatment of CCCA. 


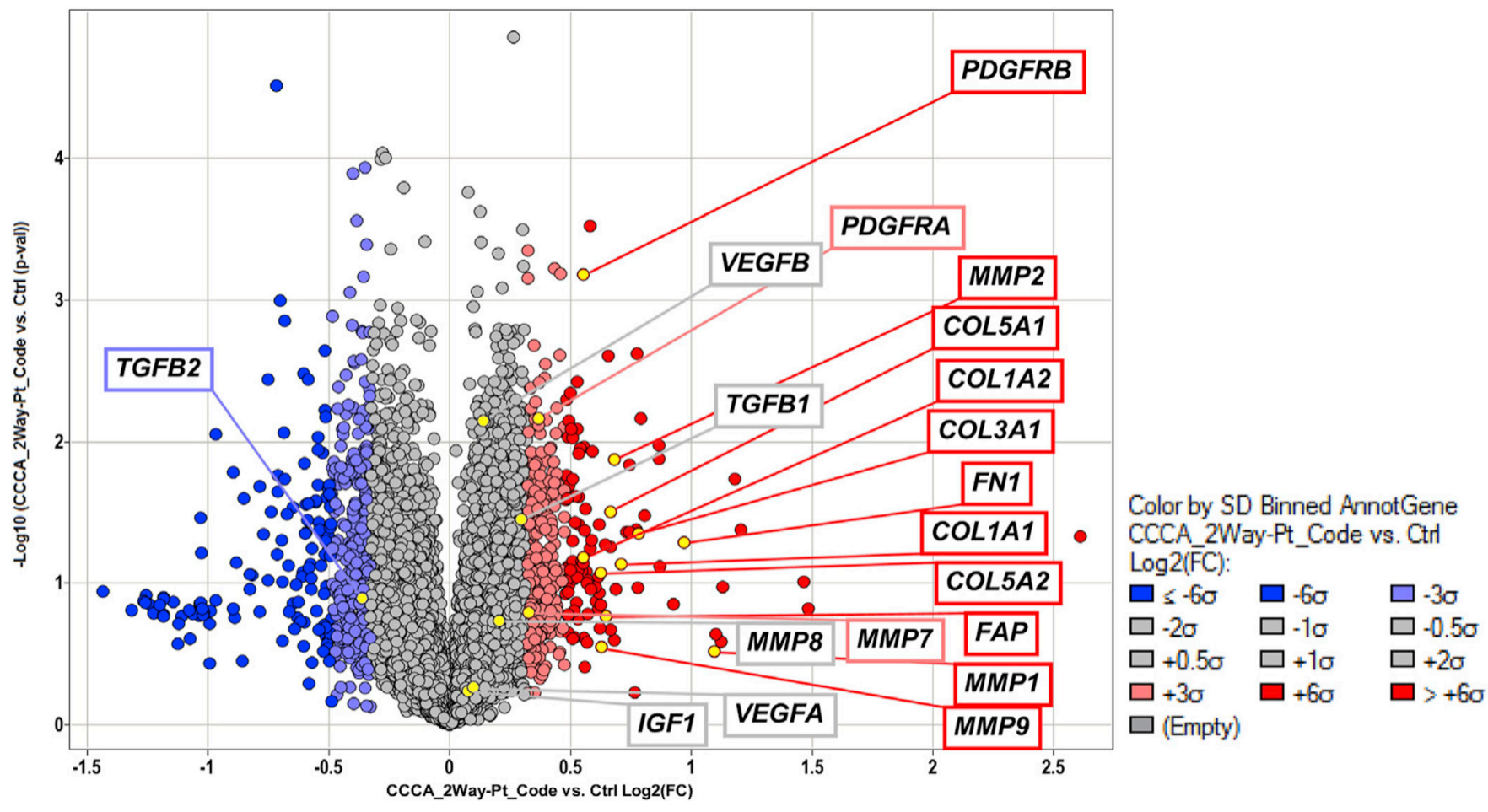

Fig 1.

A total of 21,000 genes were analyzed via microarray analysis. Fibroproliferative genes of interest are highlighted. Up-regulated genes ( $>2$ standard deviations [SDs]) are noted in red, unchanged genes $(<2 \mathrm{SDs})$ are noted in gray, and down-regulated genes are noted in blue. $C C C A$, Central centrifugal cicatricial alopecia; $C O L 1 A 1$, collagen type I alpha 1 chain gene; $C O L 1 A 2$, collagen type II alpha 1 chain gene; $C O L 3 A 1$, collagen type III alpha 1 chain gene; COL5A1, collagen type $\mathrm{V}$ alpha 1 chain gene; COL5A2, collagen type $\mathrm{V}$ alpha 2 chain gene; $C t r l$, control; FAP, fibroblast activation protein alpha gene; $F C$, fold change; $F N 1$, fibronectin 1 gene; $I G F 1$, insulin-like growth factor 1gene; $M M P 1$, matrix metallopeptidase 1 gene; $M M P 2$, matrix metallopeptidase 2 gene; $M M P 7$, matrix metallopeptidase 7 gene; $M M P 8$, matrix metallopeptidase 8 gene; $M M P 9$, matrix metallopeptidase 9 gene; $P D G F R A$, platelet derived growth factor receptor alpha gene; $P D G F R B$, platelet derived growth factor receptor beta gene; Pt, patient; TGFB1, transforming growth factor beta 1 gene; TGFB2, transforming growth factor beta 2 gene; $V E G F A$, vascular endothelial growth factor A gene; $V E G F B$, vascular endothelial growth factor B gene. 


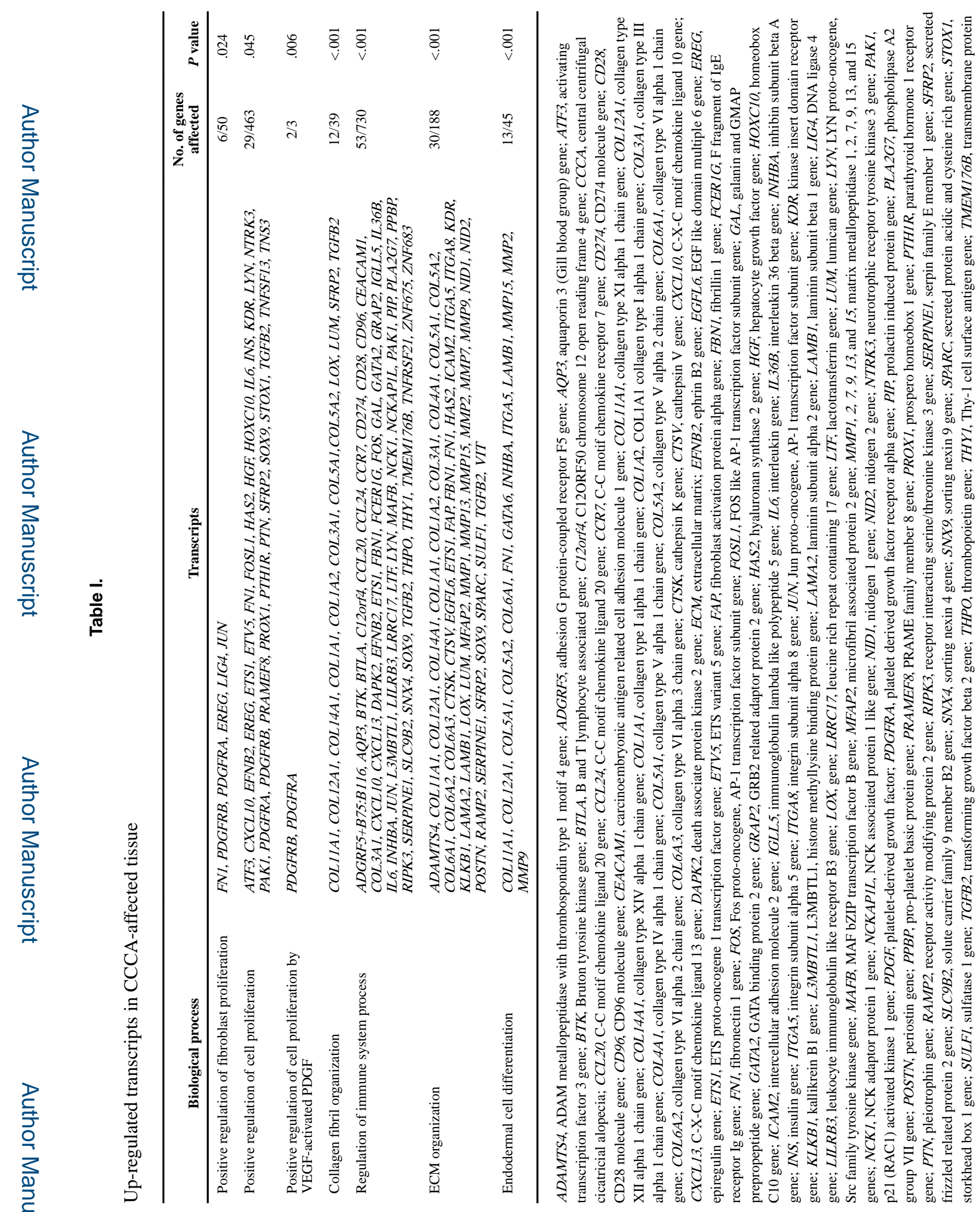

J Am Acad Dermatol. Author manuscript; available in PMC 2019 January 28. 


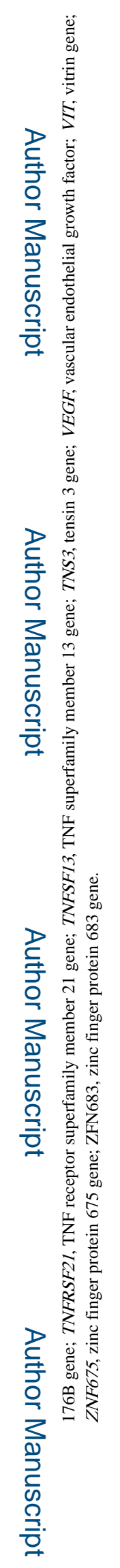

J Am Acad Dermatol. Author manuscript; available in PMC 2019 January 28. 


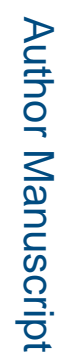

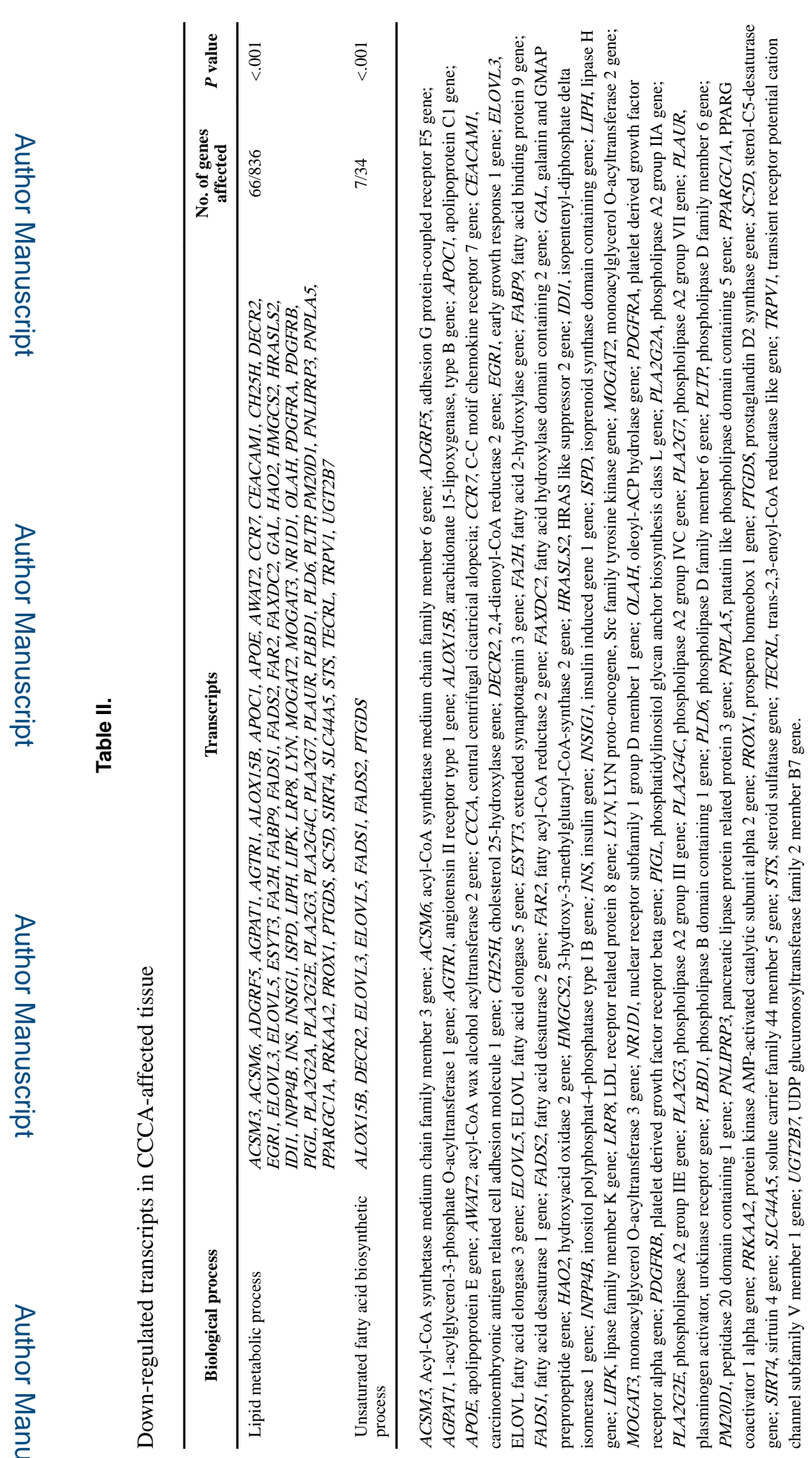

J Am Acad Dermatol. Author manuscript; available in PMC 2019 January 28. 
Table III.

Top canonic pathways displaying overlap with CCCA

\begin{tabular}{lcc}
\hline Pathway & Overlap $(\%)$ & $\boldsymbol{P}$ value \\
\hline Hepatic fibrosis/hepatic stellate cell activation & 16.5 & $<.001$ \\
Atherosclerosis signaling & 18 & $<.001$ \\
Granulocyte adhesion and diapedesis & 14.2 & $<.001$ \\
Agranulocyte adhesion and diapedesis & 12.8 & $<.001$ \\
GP6 signaling pathway & 13.8 & $<.001$ \\
\hline
\end{tabular}

$C C C A$, Central centrifugal cicatricial alopecia; $G P 6$, glycoprotein VI platelet. 


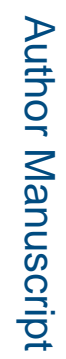

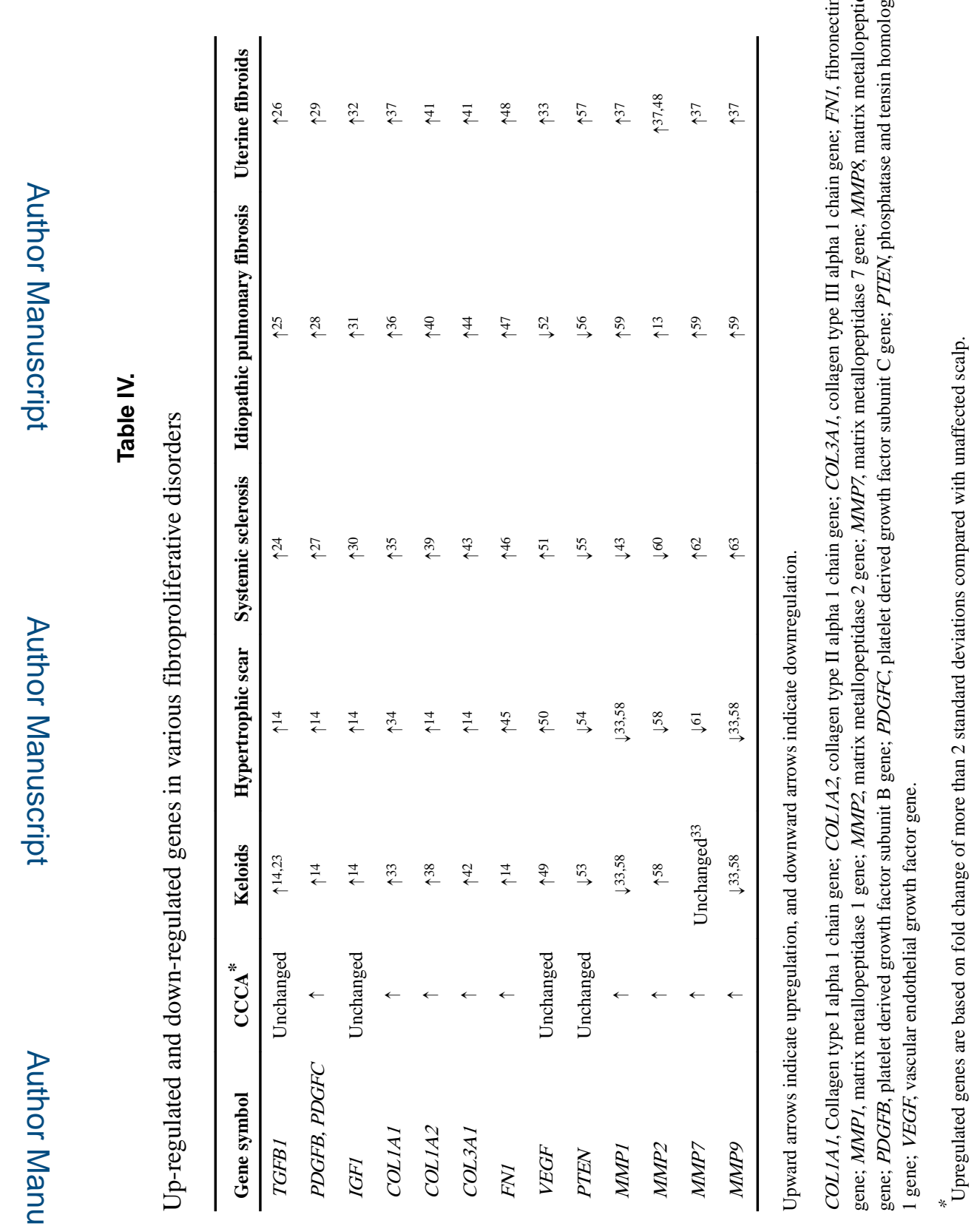

J Am Acad Dermatol. Author manuscript; available in PMC 2019 January 28. 